\title{
Keefektifan Buku Teks Tematik Berbasis Kearifan Lokal Terhadap Hasil Belajar Siswa Sekolah Dasar
}

\author{
Rizki Dwi Siswanto ${ }^{1}$, Mimin Ninawati ${ }^{2}$ \\ ${ }^{1,2}$ Program Studi Pendidikan Guru Sekolah Dasar Universitas Muhammadiyah Prof DR HAMKA \\ ${ }^{1}$ rizkidwisiswanto@uhamka.ac.id \\ 2mimin_ninawati@uhamka.ac.id
}

\begin{abstract}
ABSTRAK
Tujuan dari penelitian ini adalah untuk melihat efektifitas buku teks tematik berbasis kearifan lokal terhadap hasil belajar siswa. Metode penelitian yang digunakan dalam penelitian ini adalah kuantitatif jenis quasi-eksperiment. Pada penelitian ini menggunakan Nonequivalent control group design. Populasi di dalam penelitian ini adalah siswa kelas IV SDN 2 Surodakan, sedangkan teknik sampling menggunakan purposive sampling yaitu Kelas IV-C dan IV-D. Teknik pengumpulan data dalam penelitian ini yaitu menggunakan observasi, wawancara, dan Tes. Sedangkan analisis data menggunakan independent sample t-test. hasil penelitian yaitu berdasarkan hasil uji non-parametrik dengan uji U Mann-Whitney menunjukkan nilai Asymp.Sig.(2-tailed) sebesar 0,000 $<$ 0,05, maka hipotesis diterima. Sehingga dapat disimpulkan bahwa terdapat perbedaan yang signifikan hasil belajar siswa yang menggunakan dengan siswa yang tidak menggunakan buku teks tematik berbasis kearifan lokal.
\end{abstract}

Kata kunci: Buku Teks; Hasil Belajar; Kearifan Lokal; Pembelajaran Tematik

\section{ABSTRACT}

The purpose of this study was to see the effectiveness of thematic textbooks based on local wisdom on student learning outcomes. The research method used in this research is a quantitative type of quasi-experiment. In this study using the Nonequivalent control group design. The population in this study were fourth grade students of SDN 2 Surodakan, while the sampling technique used purposive sampling, namely Class IV-C and IV-D. Data collection techniques in this study are using observation, interviews, and tests. While the data analysis used the independent sample t-test. The results of the study are based on the results of the non-parametric test with the Mann-Whitney U test showing the Asymp.Sig. (2-tailed) value of $0.000<0.05$, then the hypothesis is accepted. So it can be concluded that there is a significant difference in the learning outcomes of students who use them with students who do not use thematic textbooks based on local wisdom.

Keywords: Textbook; Learning outcomes; Local culture; Thematic Learning

\section{PENDAHULUAN}

Pendidikan dasar merupakan tingkatan awal pendidikan yang menjadi pondasi awal untuk tingkat selanjutnya. Sebagai wujud agar proses pendidikan pada jenjang pendidikan dasar berhasil maka dibutuhkan kerjasama dari berbagai pihak yaitu dari pemerintah dan juga masyarakat. Fungsi penting dari pendidikan dasar untuk mengembangkan kemampuan awal yang menjadi modal bagi siswa ketika berada dimasyarakat nantinya. Beberapa faktor penentu keberhasilan pendidikan dasar yaitu pengelolaan proses pembelajaran. Kualitas dalam proses pembelajaran akan mencapai hasil optimal sesuai dengan tujuan pembelajaran yang telah disusun.
Pada jenjang pendidikan dasar proses pembelajaran menggunkan Kurikulum 2013. Pembelajaran tematik merupakan model pembelajaran yang di dalamnya terdapat beberapa tema pelajaran yang dirangkai secara terpadu untuk membangun pengalaman siswa yang bermakna. Pembelajaran Tematik merupakan suatu pembelajaran yang mengintegrasikan beberapa mata pelajaran sehingga menumbuhkan pengetahuan baru yang lebih kompleks (Puspita, 2017). Pada pembelajaran tematik agar materi pelajaran tersampaikan dengan optimal dibutuhkan bahan ajar. Bahan ajar yaitu suatu bahan yang digunakan guru yang di dalamnya terdapat materi pembelajaran agar kompetensi siswa 
meningkat (Puspita \& Purwo, 2019). Bahan ajar dijakan acuan siswa dalam belajar, salah satu bentuk bahan ajar yaitu buku teks. Bahan ajar berbentuk buku teks dapat membantu guru dalam mencapai tujuan pembelajaran di sekolah. Menurut Majid (2013) bahan ajar merupakan berbagai bentuk alat yang membantu guru dalam pengelolaan pembelajaran. Buku teks yang dikembangkan oleh siswa salah satunya yaitu diintegrasikan dengan nilai-nilai budaya lokal atau karifan lokal.

Kearifan lokal di dalam pembelajaran yaitu dengan memasukkan nilai-nilai baik di dalam diri siswa sehingga membentuk karakter yang baik. Menurut (Tinja, Towaf, \& Hariyono, 2017), kearifan lokal merupakan aktivitas dan kebiasaan yang dilakukan oleh masyarakat yang tertanam kuat di dalam kehidupan yang di dalamnya mengandung unsur nilai budaya yang tinggi. Jadi, kearifan lokal merupakan kearifan, pengetahuam, dan kecerdasan dalam lingkungan masyarakat tertentu. Sehingga nilainilai luhur kearifan lokal ditanamkan dan ditumbuhkan dalam probadi siswa melalui buku teks.

Buku teks berbasis kearifan lokal di dalamnya mengaitkan materi pembelajaran yang terintegrasi pembelajaran tematik dan kearifan lokal setempat. Namun kenyataan di lapangan pada implementasi Kurikulum 2013, pemerintah belum menyediakan buku siswa tentang kearifan lokal di lingkungan tempat tinggal siswa khususnya di Kabupaten Trenggalek. Pemerintah dalam hal ini Kemendikbud hanya memfasilitasi buku guru dan buku siswa yang bersifat global dan cenderung materi terlalu luas sehingga sulit dicerna oleh siswa. Materi yang terdapat di dalam buku siswa kurang bervariatif dan sangat terbatas. Diharapkan guru mampu mengembangkan buku teks berbasis kearifan lokal yang disesuaikan dengan karakteristik dan kebutuhan siswa. Menurut Avalentina (dalam Syarifuddin, dkk, 2017), Tugas guru yaitu mengembangkan bahan ajar yang kreatif serta inovatif untuk menunjang pembelajaran. Tujuan dari pengembangkan bahan ajar oleh guru yang dikaitkan denga kearifan lokal mampu meningkatkan hasil belajar siswa.

\section{METODE PENELITIAN}

Metode penelitian yang digunakan dalam penelitian ini yaitu penelitian kuantitatif dengan jenis quasi-eksperiment. Desain dalam penelitian ini yaitu menggunakan Nonequivalent control group design. Pada desain ini menggunakan 2 (dua) kelas dimana 1 (satu) kelas digunakan sebagai kelas kontrol dan 1 (satu) kelas lagi dijadikan sebagai kelas eksperimen. Pada kelas eksperimen diberikan perlakuan yaitu menggunakan buku teks berbasis kearifan lokal sedangkan kelas kontrol tidak diberikan perlakuan atau tidak menggunakan buku teks berbasis kearifan lokal. Pada masing-masing kelompok diberikan pretest di awal pertemuan dan kemudian pada akhir pertemuan diberikan postest pada kedua kelompok tersebut. Desain penelitian ditunjukkan pada Gambar 1 berikut.

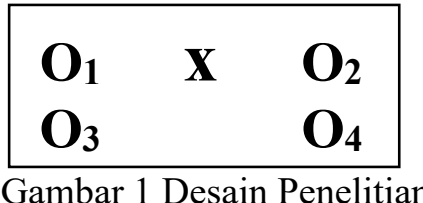

Penelitian ini dilaksanakan di SDN 2 Surodakan Kabupaten Trenggalek. Teknik pengambilan sampling menggunakan Purposive sampling yaitu dengan pertimbangan kelas kontrol dan eksperimen yang dipilih memperoleh nilai ratarata di bawah KKM berdasarkan nilai hasil belajar. dari sampling tersebut yang akan digunakan dalam peneliti ini adalah seluruh siswa kelas IV-C dan seluruh siswa kelas IV-D, dengan kelas IV-C sebagai kelas kontrol dan kelas IV-D sebagai kelas eksperimen. Jumlah siswa yang ada di kelas IV-C adalah 29 siswa, dengan rincian 14 siswa laki-laki dan 15 siswa perempuan. Sedangkan jumlah siswa yang ada di kelas IV-D adalah 30 siswa, dengan rincian 14 siswa laki-laki dan 16 siswa perempuan.

Teknik pengumpulan data dalam penelitian ini yaitu menggunakan observasi, wawancara, dan Tes. Metode observasi digunakan untuk mengetahui data melalui pengamatan dalam penggunaan buku teks tematik berbasis kearifan lokal pada siswa sekolah dasar. Wawancara digunakan untuk memperoleh informasi dalam penggunaan buku teks tematik berbasis kearifan lokal Trenggalek pada siswa sekolah dasar kelas IV. Untuk mengetahui hasil belajar siswa melalui pemberian tes di akhir pelajaran. Teknik analisis data yaitu menggunakan independent sample t-test dengan bantuan SPSS 25.0.

HASIL \& PEMBAHASAN
HASIL
Uji lapangan diterapkan pada dua kelas yaitu
kelas IV-C dan kelas IV-D di SDN 2
Surodakan. Dari kelas tersebut diperoleh bahwa
kelas IV-C dijadikan sebagai kelas kontrol
dengan responden berjumlah 29 siswa dan kelas


IV-D sebagai kelas eksperimen dengan jumlah responden berjumlah 30 siswa. Uji skala lapangan dilaksanakan pada tanggal 11 Mei 2020. Data yang diperoleh dari hasil uji skala lapangan pada nilai post-test kelas kontrol dan kelas eksperimen ditunjukkan pada Tabel 1 sebagai berikut.

Tabel 1 Nilai Hasil Belajar Siswa Kelas Kontrol dan Kelas Eksperimen

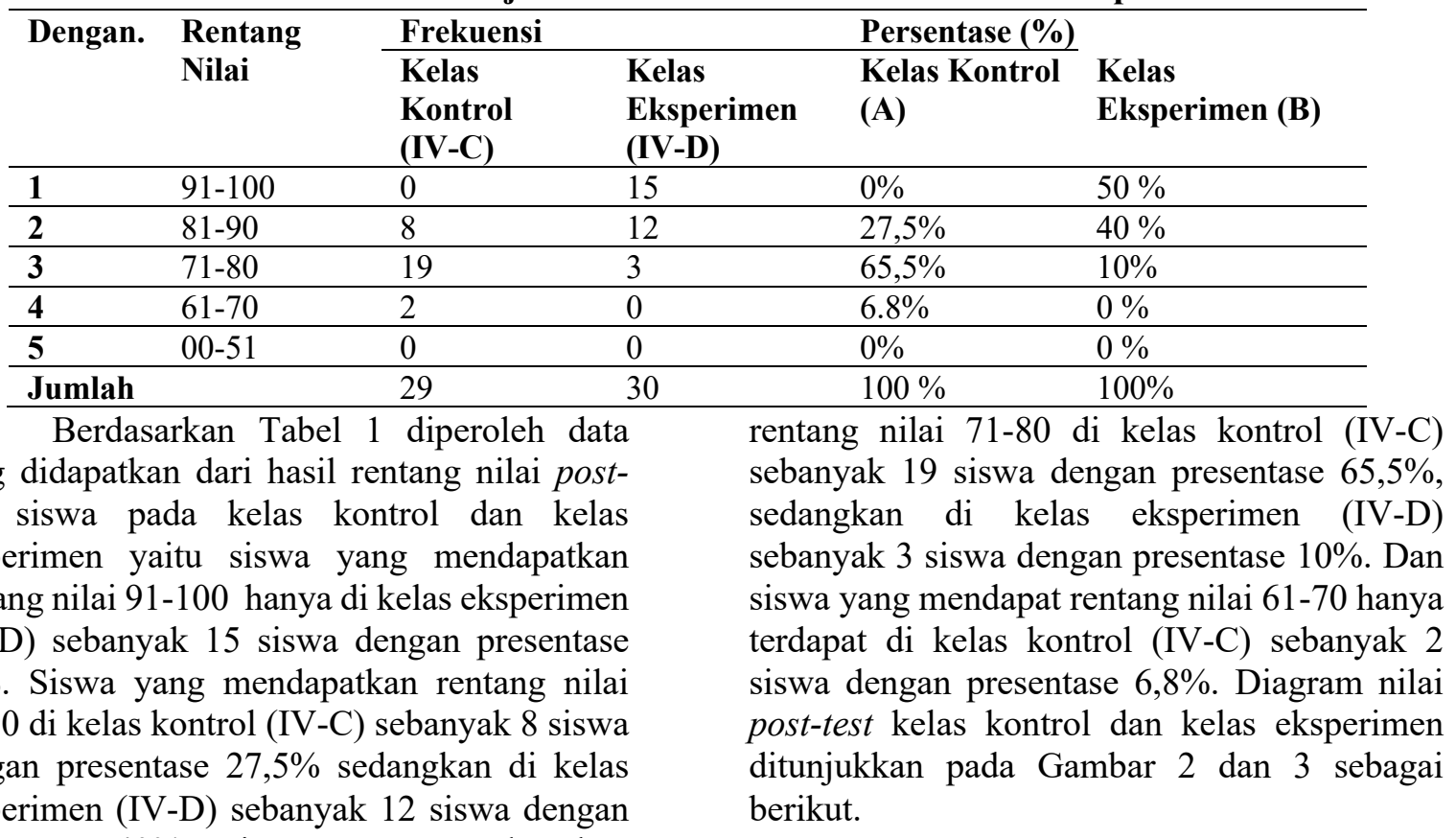

presentase $40 \%$. Siswa yang mendapatkan

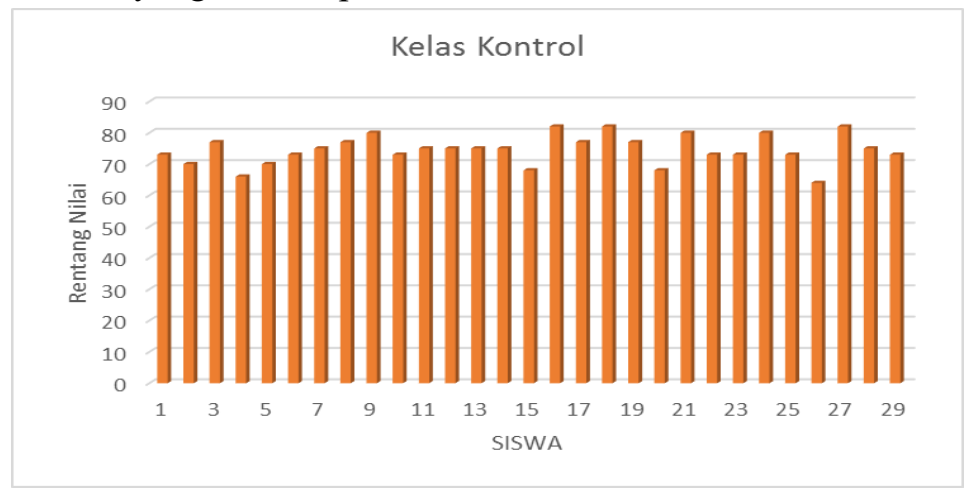

Gambar 2 Hasil Nilai Post-test Kelas Kontrol

Berdasarkan Gambar 2 diperoleh hasil nilai post-test kelas kontrol dari responden sejumlah 29 siswa rata-rata memperoleh nilai di atas 60. Hasil nilai post-test kelas eksperimen ditunjukkan pada Gambar 3 sebagai berikut.

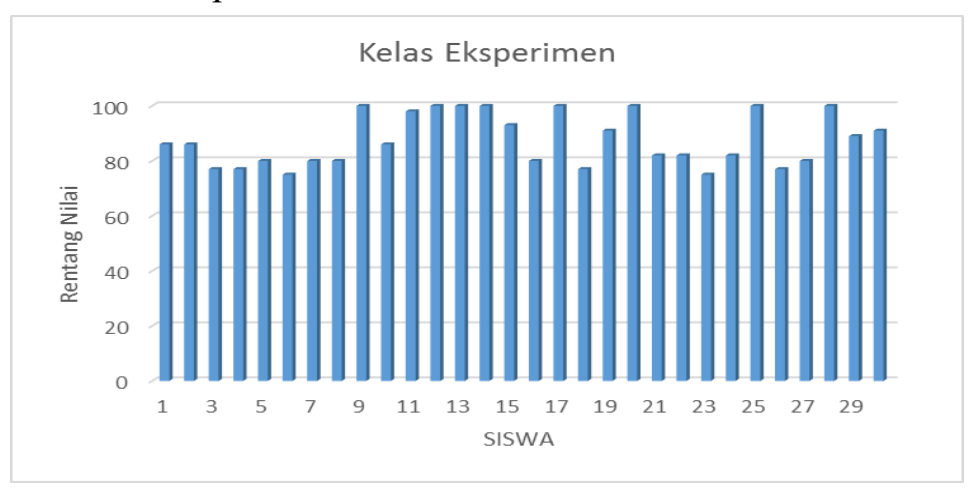

Gambar 3 Hasil Nilai Post-test Kelas Eksperimen 
Berdasarkan Gambar 3 diperoleh hasil nilai post-test kelas eksperimen dengan jumlah responden sebanyak 30 siswa rata-rata memperoleh nilai di atas 75 .

Sebelum menguji penggunaan buku teks tematik berbasis kearifan lokal Trenggalek terlebih dahulu harus terpenuhi uji prasyarat yaitu uji normalitas dan uji homogenitas.

1. Uji Normalitas
Pada uji normalitas menggunakan uji Shapiro-Wilk. Pengujian normalitas data dengan uji Shapiro-Wilk dapat dilakukan dengan menggunakan bantuan peragkat software SPSS versi 25.0. dengan signifikansi yang digunakan adalah 0,05 Dari hasil perhitungan uji normalitas yang telah dilakukan pada nilai post-test kelas kontrol dan kelas eksperimen ditunjukkan dalam Tabel 2 sebagai berikut

Tabel 2 Hasil Perhitungan Uji Normalitas

Tests of Normality

\begin{tabular}{|c|c|c|c|c|}
\hline & \multirow[b]{2}{*}{ Kelas } & \multicolumn{3}{|c|}{ Shapiro-Wilk } \\
\hline & & Statistic & Df & Sig. \\
\hline \multirow{2}{*}{$\begin{array}{l}\text { Hasil Nilai } \\
\text { Post-test }\end{array}$} & Kelas Kontrol(VI-C) & .955 & 29 & .241 \\
\hline & Kelas Eksperimen(IV-D) & .857 & 30 & .001 \\
\hline
\end{tabular}

a. Lilliefors Significance Correction

Berdasarkan Tabel 2 diperoleh data hasil perhitungan uji normalitas dengan uji Shapiro-Wilk bahwa untuk kelas kontrol mendapatkan nilai signifikan sebesar 0,241, sehingga nilai $(p>0,05)$ maka data tersebut berdistribusi normal. Sedangkan untuk kelas eksperimen mendapatkan nilai signifikan sebesar 0,001 , sehingga nilai $(\mathrm{p} \leq 0,05)$ maka data tersebut tidak distribusi normal. Maka dapat disimpulkan bahwa salah satu data tersebut terdapat perbedaan atau tidak berdistribusi normal, sehingga uji normalitas tidak terpenuhi maka tidak dilakukan uji homogenitas tetapi diuji dua perbedaan rataratanya dianalisis menggunakan uji statistik Non-Parametric dengan uji U Mann-Whitney.

2. Uji perbedaan Dua Rata-rata

Uji perbedaan dua rata-rata bertujuan melihat setara atau tidak kemampuan siswa. Berdasarkan uji normalitas yang telah dilakukan diketahui bahwa terdapat salah satu data yang tidak berdistribusi normal, sehingga dilaksanakan uji statistik Non-Parametric dengan uji U Mann-Whitney. Hasil uji tersebut ditunjukkan dalam Tabel 3 sebagai berikut.

Tabel 3 Hasil Uji Non-Parametrik U Mann- Whitney
Test Statistics ${ }^{\text {a }}$
\begin{tabular}{|l|l|}
\hline \multicolumn{2}{|l|}{ Hasil Nilai Post-test } \\
\hline Mann-Whitney U & 85.000 \\
Wilcoxon W & 520.000 \\
Z & -5.341 \\
Asymp. Sig. (2-tailed) & .000 \\
\hline
\end{tabular}

a. Grouping Variable: Kelas

Berdasarkan Tabel 3 di atas diperoleh bahwa hasil uji non-parametrik dengan menggunakan uji Mann-Whitney memperoleh hasil yaitu nilai signifikansinya adalah 0,000 . Sehingga dapat disimpulkan bahwa terdapat perbedaan hasil belajar siswa sebelum dan sesudah penggunaan buku teks berbasis kearifan lokal.

\section{Uji Hipotesis}

Tujuan uji hipotesis yaitu untuk menguji hipotesis penelitian yang telah diajukan. Uji hipotesis yaitu menggunakan uji non parametric Mann-Whitney. Pedoman pengambilan keputusan melalui Uji MannWhitney yaitu:

a. Jika nilai Asymp.Sig. $<0,05$ maka hipotesis diterima

b. Jika nilai Asymp.Sig. $>0,05$ maka hipotesis ditolak

Hipotesis hasil belajar ditunjukkan pada Tabel 4 di bawah 


\section{Tabel 4 Hasil Uji Hipotesis Hasil Belajar Siswa}

\begin{tabular}{cc}
\multicolumn{2}{c}{ Test Statistics $^{\mathbf{b}}$} \\
\hline hasil_bel_2 - hasil_bel_1 \\
\hline$Z$ & $-5.151^{\mathrm{a}}$ \\
Asymp. Sig. (2-tailed) & .000 \\
\hline
\end{tabular}

a. Based on negative ranks.

b. Wilcoxon Signed Ranks Test

Berdasarkan hasil uji non-parametrik dengan uji U Mann-Whitney pada Tabel 4 didapatkan hasil yaitu nilai Asymp.Sig.(2tailed) sebesar $0,000<0,05$, maka hipotesis diterima. Sehingga dapat disimpulkan bahwa

\section{PEMBAHASAN}

Penggunaan buku teks tematik berbasis berbasis kearifan lokal berpengaruh terhadap hasil belajar siswa. Hal tersebut dapat dilihat dari membandingkan hasil belajar siswa pada kelas kontrol dan eksperimen yang memperoleh hasil yaitu terdapat perbedaan hasil belajar siswa kelas yang menggunakan buku teks termatik berbasis kearifan lokal dengan siswa yang tidak menggunakan buku teks termatik berbasis kearifan lokal. Dengan demikian, pengembangan buku teks tematik berbasis kearifan lokal Trenggalek sangat sesuai untuk digunakan sebagai buku penunjang di sekolah dasar. Buku teks ini dapat meningkatkan hasil belajar siswa.

Buku teks berbasis kearifan lokal dapat digunakan sebagai bahan ajar penunjang atau pendamping bahan ajar utama di dalam pembelajaran. Menurut Muzanni, Zinnurain, \& Muzanni (2017), buku ajar berbasis kearifan lokal layak digunakan di dalam proses pembelajaran serta mampu meningkatkan hasil belajar siswa. Penelitian ini dikuatkan oleh Arsanti (2018) yang menyatakan bahwa modul berbasis kearifan lokal mampu meningkatkan pengetahuan siswa tentang materi yang dipelajari oleh siswa. Buku teks berbasis kearifan lokal yang diimplementasikan di dalam pembelajaran akan meningkatkan hasil belajar siswa. Menurut (Minawati, 2020), nilainilai kearifan lokal budaya yang diimplementasikan dalam pembelajaran dijadikan sebagai cara untuk mentransformasikan nilai-nilai budaya sehingga menciptakan pembelajaran yang bermakna.

Buku teks berbasis kearifan lokal mempunyai manfaat dalam meningkatkan kompetensi dan hasil belajar. Pengembangan kecakapan hidup siswa ditanamkam menggunakan model pendidikan berbasis terdapat perbedaan yang signifikan hasil belajar siswa yang menggunakan dengan siswa yang tidak menggunakan buku teks tematik berbasis kearifan lokal.

kearifan lokal yang disesuaikan masing-masing daerah (Ferdianto \& Setiyani, 2018). Pada jenjang pendidikan yang dikelola menggunakan pendekatan tematik dan lintas mata pembelajaran bertujuan untuk mengembangkan pengetahuan, keterampilan, dan sikap serta diapresiasi melalui keragaman budaya lokal (Shufa, Naela, 2018). Hasil penelitian ini dikuatkan oleh Mulyasa (dalam Wulanzani, Lestari, \& Syamsyuri, 2016), pengembangan buku harus menunjang pelaksanaan pembelajaran dan mampu membantu siswa mencapai kompetensi dalam pembelajaran secara utuh. Menurut Tinja et al., 2017) buku teks tematik dapat digunakan guru sebagai sumber belajar yang disesuaikan dengan karakteristik serta kondisi belajar siswa. Buku teks yang memadai akan mengatasi kesulitan belajar, sehingga menciptakan pembelajaran yang efektif dan efisien yang nantinya meningkatkan hasil belajar. Faktor yang menentukan keberhasilan, kebermaknaan, serta hasil belajar siswa salah satunya yaitu seberapa jauh tingkat pemahaman siswa dalam memahami materi pelajaran (Rohmah Julianti \& Mawardi, 2018). Sehingga dapat disimpulkan jika pengelolaan pembelajaran baik menggunakan buku atau alat yang lainnya yang diintegrasikan dengan kearifan lokal efektif mampu mengembangkan dan berpengaruh terhadap hasil belajar.

\section{KESIMPULAN \& SARAN}

Pengembangan Buku teks tematik berbasis kearifan lokal ini melalui analisis kebutuhan serta karakteristik siswa yang beragam. Nilai hasil belajar siswa setelah menggunakan buku teks tematik berbasis kearifan lokal yaitu sebanyak $90 \%$ siswa memperoleh nilai di atas 75. Kemudian berdasarkan hasil uji hipotesis pada kelas kontrol dan kelas eksperimen menunjukkan 
bahwa terdapat perbedaan yang signifikan hasil belajar siswa yang menggunakan buku teks tematik berbasis kearifan lokal dengan siswa yang tidak menggunakan buku teks tematik berbasis kearifan lokal. Sehingga dapat disimpulkan bahwa buku teks tematik berbasis kearifan lokal efektif meningkatkan hasil belajar siswa sekolah dasar.

$$
\text { Guru sebaiknya mampu }
$$

mengembangkan dan menjadikan Buku teks tematik berbasis kearifan lokal sebagai buku penunjang di dalam pembelajaran. Karena buku teks yang dikembangkan sendiri oleh guru berdasarkan analisis kebutuhan, karakteristik, serta kondisi sosial budaya siswa akan dapat mengoptimalkan kompetensi siswa dikarenakan materi yang diajarkan lebih mudah dipahami oleh siswa. Selanjutnya buku teks tematik berbasis kearifan lokal diharapkan tidak hanya meningkatkan hasil belajar namun juga mampu meningkatkan keaktifan dan karakter siswa sekolah dasar.

\section{DAFTAR PUSTAKA}

Arsanti, M. (2018). Pengembangan Bahan Ajar Mata Kuliah Penulisan Kreatif Bermuatan Nilai-Nilai Pendidikan Karakter Religius Bagi Mahasiswa Prodi Pbsi, Fkip, Unissula. KREDO : Jurnal Ilmiah Bahasa Dan Sastra, 1(2), 71-90. https://doi.org/10.24176/kredo.v1i2.2107

Ferdianto, F., \& Setiyani, S. (2018). Pengembangan Bahan Ajar Media Pembelajaran Berbasis Kearifan Lokal Mahasiswa Pendidikan Matematika. JNPM (Jurnal Nasional Pendidikan Matematika), 2(1), 37. https://doi.org/10.33603/jnpm.v2i1.781

Majid, A. (2013). Strategi Pembelajaran. Bandung: Remaja Rosdakarya.

Minawati, M. (2020). Potensi Penerapan NilaiNilai Budaya Lokal Pada Pembelajaran Matematika Di Sekolah Dasar. Jurnal Math-UMB.EDU, $7(2)$. https://doi.org/10.36085/mathumb.edu.v7i2.672

Muzanni, A., Zinnurain, \& Muzanni, A. (2017). Pengembangan Buku Ajar Berbasis Kearifan Lokal pada Siswa kelas v Sekolah Dasar. Jurnal Ilmiah IKIP Mataram, 4(2), 63-69. Retrieved from http://jurnal.ikipmataram.ac.id/index.php/ jiim/article/view/192\%0Ahttp://ojs.ikipm ataram.ac.id/index.php/jiim/article/view/ 192

Puspita, A. M. I. (2017). pengaruh penggunaan bahan ajar tematik berbasis lingkungan terhadap hasil belajar siswa kelas II SDN III Tanggung. STKIP PGRI Trenggalek, $3(1), 39-48$.

Puspita, A. M. I., \& Purwo, S. (2019). Pengaruh Bahan Ajar Berbasis Literasi Dengan Pendekatan Kontekstual Terhadap Hasil Belajar Siswa Sekolah Dasar. Al-Aulad: Journal of Islamic Primary Education, 2(1), 1-7. https://doi.org/10.15575/alaulad.v2i1.4426

Rohmah Julianti, I. A., \& Mawardi, M. (2018). Penerapan Desain Pembelajaran Tematik Integratif Alternatif Berbasis Subsubtema untuk Meningkatkan Kebermaknaan dan Hasil Belajar. Publikasi Pendidikan, 8(3), 206. https://doi.org/10.26858/publikan.v8i3.65 98

Shufa, Naela, K. F. (2018). Pembelajaran Berbasis Kearifan Lokal di Sekolah Dasar: Sebuah Kerangka Konseptual. Jurnal Ilmiah Kependidikan, 1(1), 48-53.

Tinja, Y., Towaf, S. M., \& Hariyono, H. (2017). Pengembangan Bahan Ajar Tematik Berbasis Kearifan Lokal Sebagai Upaya Melestarikan Nilai Budaya Pada Siswa Sekolah Dasar. Jurnal Pendidikan: Teori, Penelitian, Dan Pengembangan, 2(9), 1257-1261.

Wulanzani, U. T., Lestari, U., \& Syamsyuri, I. (2016). Hasil validasi buku teks matakuliah biotekologi berbasis bahan alam tanaman pacing (costus speciosus smith) sebagai antifertilitas. Jurnal Pendidikan: Teori, Penelitian, Dan Pengembangan, l(9), 1830-1835. 